\title{
Karakteristik Klinikopatologik Pasien Kanker Payudara dengan Metas- tasis Tulang di RSUP Sanglah pada Tahun 2014 - 2018
}

\section{Putu Krishna B. S. Putra, ${ }^{1}$ I Wayan J. Sumadi, ${ }^{2}$ Ni Putu Sriwidyani, ${ }^{2}$ IG Budhi Setiawan ${ }^{3}$}

\author{
${ }^{1}$ Program Studi Pendidikan Dokter Fakultas Kedokteran Universitas Udayana Denpasar \\ ${ }^{2}$ Departemen/KSM Patologi Anatomi Fakultas Kedokteran Universitas Udayana/RSUP \\ Sanglah Denpasar \\ ${ }^{3}$ Departemen/KSM Bedah Fakultas Kedokteran Universitas Udayana/RSUP Sanglah \\ Denpasar \\ Email: b.bayu60@yahoo.com
}

\begin{abstract}
Breast cancer is the most common cancer in woman. Metastasis often occurs especially to the bones. This study was aimed to determine the characteristics of breast cancer patients with bone metastasis. This was a descriptive study with a cross-sectional design. Samples were 46 breast cancer patients with bone metastasis recorded at Sanglah Hospital from 2014 until 2018. Data of pathological examination archives of Oncology Surgery Division Medical Faculty of Udayana University/Sanglah General Hospital were used to obtain the clinicopathological characteristics of metastatic breast cancer patients based on age, lateralization, histopathological type, and tumor molecular subtype. The results showed that most cases of metastatic breast cancer were aged 40-49 years as many 21 patients (45.7\%), minimal difference in lateralization between right breast as many 22 patients $(47.8 \%)$ and left breast 23 patients $(50 \%)$. The most common histopathological type was invasive carcinoma of no special type as many 34 patients (73.9\%). The most common tumor subtype was the luminal B subtype as many 21 patients (45.7\%). In conclusion, most patients of breast cancer with bone metastasis were 40-49 years old, invasive carcinoma of no special type, molecular subtype of luminal B, and no significant difference between lateralization to the right and left breast.
\end{abstract}

Keywords: breast cancer, bone, metastasis, clinicopathological caharacteristics

\begin{abstract}
Abstrak: Kanker payudara merupakan jenis kanker yang paling sering dijumpai pada wanita. Metastasis sering terjadi terutama pada tulang. Penelitian ini bertujuan untuk mengetahui karakteristik pasien kanker payudara dengan metastasis tulang di RSUP Sanglah Denpasar. Jenis penelitian ialah deskriptif dengan desain potong lintang. Sampel penelitian ialah 46 pasien kanker payudara dengan metastasis tulang yang tercatat di RSUP Sanglah tahun 2014-2018. Data diambil dari arsip hasil pemeriksaan patologi di Subdivisi Bedah Onkologi, Departemen/Kelompok Staf Medis (KSM) Bedah Fakultas Kedokteran Universitas Udayana (FK UNUD)/RSUP Sanglah untuk mendapatkan karakteristik klinikopatologi pasien kanker payudara metastasis tulang berdasarkan usia, lateralisasi, tipe histopatologik, dan subtipe molekuler tumor. Hasil penelitian menunjukkan kasus terbanyak terjadi pada rentang usia 40-49 tahun sebanyak 21 orang (45,7\%), dengan lateralisasi tidak jauh berbeda antara payudara kanan sebanyak 22 orang $(47,8)$ dan kiri sebanyak 23 orang $(50 \%)$. Tipe histopatologik yang lebih sering ditemukan yaitu invasive carcinoma of no special type sebanyak 34 orang (73,9\%). Subtipe molekuler yang paling banyak ditemukan ialah subtipe luminal B sebanyak 21 orang $(45,7 \%)$. Simpulan penelitian ini pasien kanker payudara dengan metastasis tulang berada pada rentang usia 40-49 tahun, invasive carcinoma of no special type, subtipe molekuler luminal B. dan lateralisasi payudara kanan dan kiri tidak jauh berbeda.
\end{abstract}

Kata kunci: kanker payudara, metastasis, tulang, karakteristik klinikopatologik 


\section{PENDAHULUAN}

Kanker payudara merupakan jenis kanker yang paling sering terjadi pada wanita di berbagai negara di dunia, termasuk negara berkembang. Kanker terjadi karena adanya sel yang tumbuh secara tidak normal dan tidak terkendali serta dapat menyerang organ lain. Kasus kanker payudara di Uni Eropa pada tahun 2006 ialah 109,8/100.000 wanita, dengan mortalitas 38,4/100.000 wanita per tahun. Sebanyak 1,38 juta kasus baru dan 458.000 kematian akibat kanker payudara didapat-kan pada tahun 2008. Kasus kanker mulai menurun menjadi 1,5\% per tahun sejak tahun 1990. Tingkat kematian akibat kanker payudara telah menurun dengan cepat di sebagian besar negara Barat sejak awal 1990-an karena kemajuan dunia kesehatan dalam mendeteksi adanya kanker payudara, namun kanker payudara masih merupakan penyebab utama kematian akibat kanker pada wanita. ${ }^{1}$

Kanker dapat mengalami penyebaran ke bagian tubuh lain (metastasis). Sel kanker menyebar ke bagian tubuh selain pada tempat pertama kanker tersebut berkembang seperti hati, paru-paru, tulang, dan otak. Sel kanker kembali membelah dan tumbuh di luar kendali dan membentuk tumor baru. Meskipun tumor baru tumbuh di bagian tubuh lain, kanker di tempat sebelumnya akan tetap ada., ${ }^{2,3}$

Pasien kanker payudara yang telah mengalami metastasis saat diagnosis ialah sekitar 4-6\%, dan hanya sekitar seperlima dari angka tersebut yang akan bertahan selama 5 tahun. Angka kelangsungan hidup tersebut dipengaruhi oleh berbagai faktor prognosis. Kanker payudara nodus positif akan mengalami kekambuhan hingga sebesar $70 \%$, sedangkan angka kekambuhan pada nodus negatif sebesar $30 \%$. Prevalensi penyakit metastasis cukup tinggi karena banyak wanita hidup dengan penyakit ini selama beberapa tahun. ${ }^{1}$

Salah satu tempat metastasis yang paling sering ditemukan pada kanker payudara yaitu tulang. Terdapat lebih dari 50\% pasien kanker payudara stadium lanjut mengalami metastasis ke tulang. Pasien yang mengalami metastasis ke tulang akan memiliki gejala seperti nyeri, patah tulang, kompresi medula spinalis, dan tingkat kalsium dalam darah yang tinggi. Nyeri tulang merupakan gejala awal pada pasien metastasis tulang. Rasa nyeri biasanya dimulai hanya sebentar, paling buruk di malam hari dan biasanya nyeri dapat menurun dengan bergerak. ${ }^{4,5}$

Angka kejadian kasus kanker payudara yang tinggi, risiko untuk mengalami metastasis, dan angka mortalitas yang tinggi, serta data mengenai kasus metastasis kanker payudara ke tulang di Bali yang masih terbatas, mendorong penulis untuk mendapatkan prevalensi dan gambaran karakteristik pasien dengan kanker payudara metastasis tulang di Rumah Sakit Umum Pusat (RSUP) Sanglah dalam periode tahun 2014 sampai tahun 2018 berdasarkan data rekam medik pasien.

\section{METODE PENELITIAN}

Penelitian ini merupakan penelitian deskriptif dengan dessain potong lintang. Tujuan penelitiann ialah untuk mendapatkan prevalensi dan karakteristik pasien kanker payudara dengan metastasis tulang di RSUP Sanglah tahun 2014 s/d tahun 2018. Sampel penelitian ialah 46 penderita kanker payudara dengan metastasis tulang yang tercatat di RSUP Sanglah pada tahun 2014 s/d tahun 2018.

Data penelitian diambil dari arsip hasil pemeriksaan patologi di Subdivisi Bedah Onkologi, Departemen/Kelompok Staf Medis (KSM) Bedah Fakultas Kedokteran Universitas Udayana (FK UNUD)/RSUP Sanglah. Data karakteristik berupa usia, lateralisasi, tipe histologik, dan profil imunohistokimia dikategorikan sesuai tujuan penelitian. Data diolah secara univariat untuk mendapatkan frekuensi dan persentase masing-masing kategori yang disajikan dalam bentuk narasi dan tabel.

Penelitian ini telah mendapat persetujuan dari Komisi Etik Penelitian Kesehatan Fakultas Kedokteran Universitas Udayana/ Rumah Sakit Umum Pusat (RSUP) Sanglah Denpasar, Bali dengan Nomor. 1842/UN. 14.2.2.VII. 14/LP/2019 


\section{HASIL PENELITIAN}

Total pasien kanker payudara yang tercatat dalam data pasien kanker payudara di Subdivisi Bedah Onkologi Departemen/KSM Bedah FK UNUD/RSUP Sanglah Denpasar dari tahun 2014 s/d tahun 2018 berjumlah 1.417 kasus. Kasus kanker payudara yang mengalami meta-stasis tulang sebanyak 83 kasus, sedangkan yang memenuhi kriteria inklusi serta kriteria eksklusi yang telah ditetapkan ialah 46 kasus. Sebagian kasus dari total 46 pasien metastasis tulang tersebut juga mengalami metastasis multipel pada organ lain disamping pada tulang, seperti paru, hati, dan otak. Metastasis tertinggi terjadi pada tulang saja sebanyak 22 kasus $(47,8 \%)$, disusul dengan metastasis tulang dan paru sebanyak 14 kasus (30,4\%); metastasis tulang dan hati sebanyak 5 kasus $(10,9 \%)$; metastasis tulang, paru, dan hati sebanyak 4 kasus $(8,7 \%)$; dan mestastasis tulang, paru, dan otak sebanyak 1 kasus $(2,2 \%)$.

Tabel 1 memperlihatkan bahwa rentang usia 40-49 tahun dan 50-59 tahun merupakan kelompok usia terbanyak, yakni 21 pasien $(45,7 \%)$ dan 16 pasien $(15,2 \%)$ secara berturut.

Tabel 1. Distribusi kasus pasien kanker payudara dengan metastasis tulang di RSUP Sanglah pada tahun 2014-2018 berdasarkan karakteristik usia

\begin{tabular}{ccc}
\hline $\begin{array}{c}\text { Usia } \\
\text { (tahun) }\end{array}$ & $\begin{array}{c}\text { Frekuensi } \\
(\mathbf{n = 4 6 )}\end{array}$ & $\begin{array}{c}\text { Persentase } \\
(\mathbf{\%})\end{array}$ \\
\hline $20-29$ & 2 & 4,3 \\
$30-39$ & 1 & 2,2 \\
$40-49$ & 21 & 45,7 \\
$50-59$ & 16 & 34,8 \\
$\geq 60$ & 6 & 13 \\
\hline
\end{tabular}

Tabel 2 memperlihatkan bahwa lateralisasi tumor di bagian payudara kanan terdapat pada 22 pasien $(47,8 \%)$ dan lateralisasi tumor di bagian payudara kiri pada 23 pasien (50\%), sedangkan kasus kanker payudara pada payudara kanan dan kiri hanya didapatkan pada 1 kasus $(2,2 \%)$.
Tabel 2. Distribusi kasus pasien kanker payudara dengan metastasis tulang di RSUP Sanglah pada tahun 2014-2018 berdasarkan lateralisasi

\begin{tabular}{ccc}
\hline $\begin{array}{c}\text { Lateralisasi } \\
\text { payudara }\end{array}$ & $\begin{array}{c}\text { Frekuensi } \\
(\mathbf{n = 4 6})\end{array}$ & $\begin{array}{c}\text { Persentase } \\
(\boldsymbol{\%})\end{array}$ \\
\hline Kanan & 22 & 47,8 \\
Kiri & 23 & 50 \\
Kanan-kiri & 1 & 2,2 \\
\hline
\end{tabular}

Tabel 3 memperlihatkan bahwa berdasarkan tipe histopatologik, didapatkan invasive carcinoma of no special type pada 34 pasien $(73,9 \%)$, dan invasive lobular carcinoma pada 12 pasien $(26,1 \%)$.

Tabel 3. Distribusi kasus pasien kanker payudara dengan metastasis tulang di RSUP Sanglah pada tahun 2014-2018 berdasarkan tipe histopatologik

\begin{tabular}{lcc}
\hline \multicolumn{1}{c}{$\begin{array}{c}\text { Tipe } \\
\text { histopatologik }\end{array}$} & $\begin{array}{c}\text { Frekuensi } \\
(\mathbf{n = 4 6 )}\end{array}$ & $\begin{array}{c}\text { Persentase } \\
(\mathbf{\%})\end{array}$ \\
\hline $\begin{array}{l}\text { Invasive carcino- } \\
\text { ma of no special } \\
\text { type }\end{array}$ & 34 & 73,9 \\
$\begin{array}{l}\text { Invasive lobular } \\
\text { carcinoma }\end{array}$ & 12 & 26,1 \\
\end{tabular}

Tabel 4 memperlihatkan penggolongan subtipe molekuler tumor berdasarkan hasil pemeriksaan profil imunohistokimia ER, PR, HER-2, dan Ki67.

Tabel 4. Distribusi frekuensi kasus pasien kanker payudara dengan metastasis tulang di RSUP Sanglah pada tahun 2014-2018 berdasarkan profil imunohistokimia

\begin{tabular}{lcc}
\hline Status reseptor & $\begin{array}{c}\text { Frekuensi } \\
(\mathbf{n = 4 6})\end{array}$ & $\begin{array}{c}\text { Persentase } \\
(\mathbf{\%})\end{array}$ \\
\hline Estrogen reseptor & & \\
$\quad+$ & 32 & 69,6 \\
$\quad-$ & 14 & 30,4 \\
Progesteron & & \\
reseptor & & \\
$\quad+$ & 30 & 65,2 \\
- & 16 & 34,8 \\
HER-2 & & \\
$\quad+$ & 27 & 58,7 \\
- & 19 & 41,3 \\
Ki67 & & \\
$\quad$ Tinggi & 24 & 52,2 \\
$\quad$ Rendah & 22 & 47,8 \\
\hline
\end{tabular}


Tabel 5 memperlihatkan penggolongan subtipe dikategorikan berdasarkan ER/PR (+), HER-2 (-), dan Ki67 rendah tergolong luminal A; ER/PR (+), HER (-), Ki67 tinggi atau ER/PR (+), HER (+), Ki67 tinggi/rendah tergolong luminal B; ER/PR (), HER-2 (+) dan Ki67 tinggi/rendah tergolong HER-2 positif; dan ER/PR (-), HER-2 (-) dan Ki67 tinggi/rendah tergolong triple negatif.

Tabel 5. Penggolongan subtipe kanker payudara berdasarkan profil imunohistokimia

\begin{tabular}{lccc}
\hline \multicolumn{1}{c}{ Subtipe } & ER/PR & HER-2 & Ki67 \\
\hline Luminal A & + & - & Rendah \\
Luminal B & + & - & Tinggi \\
& + & + & Rendah/Tinggi \\
HER-2 & - & + & Rendah/Tinggi \\
Triple & - & - & Rendah/Tinggi \\
negative & & & \\
\hline
\end{tabular}

Tabel 6 memperlihatkan bahwa subtipe terbanyak yang ditemukan yaitu subtipe Luminal B pada 21 pasien $(45,7 \%)$, dan yang terendah yaitu tipe triple negatif pada 1 pasien $(2,2 \%)$.

Tabel 6. Distribusi frekuensi kasus pasien kanker payudara dengan metastasis tulang di RSUP Sanglah pada tahun 2014-2018 berdasarkan subtipe

\begin{tabular}{lcc}
\hline Subtipe & $\begin{array}{c}\text { Frekuensi } \\
(\mathbf{n = 4 6 )}\end{array}$ & $\begin{array}{c}\text { Persentase } \\
(\mathbf{\%})\end{array}$ \\
\hline Luminal A & 15 & 32,6 \\
Luminal B & 21 & 45,7 \\
HER-2 & 9 & 19,6 \\
Triple & 1 & 2,2 \\
negative & & \\
\hline
\end{tabular}

\section{BAHASAN}

Pada penelitian ini didapatkan jumlah pasien terbanyak berada pada rentang usia 40-49 tahun (45,7\%), disusul usia 50-59 tahun $(34,8 \%)$, dan yang terendah ialah 30 39 tahun $(2,2 \%)$ yang hampir sama dengan rentang usia 20-29 tahun (4,3\%). Hasil penelitian ini sejalan dengan penelitian yang dilakukan di Rumah Sakit Umum DR. Wahidin Sudiharsono Makasar yang menyatakan rentang usia 40-49 tahun merupakan rentang usia tertinggi. ${ }^{6}$ Risiko terjadi- nya kasus kanker payudara pada wanita di atas 30 tahun lebih tinggi dan risiko ini akan bertambah seiring usia lanjut dan setelah menopause. $^{7}$

Lateralisasi kanker payudara dibagi menjadi dua yaitu lateralisasi payudara kanan dan payudara kiri. Lokasi payudara ini merujuk kepada tempat pertama tumor berasal sebelum bermetastasis ke tulang. Hasil data kedua kelompok lateralisasi tidak jauh berbeda, yaitu 47,8\% pasien terdapat pada payudara kanan dan $50 \%$ pasien terdapat pada payudara bagian kiri, sedangkan $2,2 \%$ pasien terdapat pada kedua payudara. Hasil penelitian ini selaras dengan penelitian yang dilakukan di RS St. Elisabeth Medan tahun 2011-2013 yang mendapatkan lateralisasi tertinggi pada payudara kiri $(52 \%)$ dan yang paling rendah pada payudara kanan dan kiri $(3,9 \%){ }^{8}$ Penelitian yang dilakukan di Cina Selatan juga menunjukkan adanya kese-suaian dengan hasil penelitian ini, dimana disebutkan bahwa dari 8.901 pasien kanker payudara dengan metastasis tulang, sebesar 4.127 kasus $(46,4 \%)$ terdapat pada payudara kanan sedangkan pada payudara kiri tidak berbanding jauh yaitu sebesar 4.292 kasus (48,2\%), dan sebanyak 482 kasus $(5,2 \%)$ didapatkan pada payudara kanan dan kiri. ${ }^{9}$

Tipe invasive carcinoma of no special type didapatkan lebih banyak pada pasien kanker payudara dengan metastasis tulang dibandingkan tipe invasive lobular carcino$m a(73,9 \%$ vs $26,1 \%)$. Hasil penelitian ini menunjukkan adanya kesesuaian data dengan penelitian yang dilakukan di RSUP Prof. Dr. R. D. Kandou Manado yaitu tipe invasive carcinoma of no special typel invasive ductal carcinoma merupakan tipe tersering ditemukan $(97,6 \%)$, diikuti tipe invasive lobular carcinoma (0,6\%). Sebanyak 96 dari 147 kasus kanker payudara berada pada stadium IV dimana pada stadium ini telah terjadi metastasis ke organ lain. ${ }^{10}$ Invasive carcinoma of no special type merupakan jenis tipe kanker yang paling sering dijumpai. Sekitar $80 \%$ kanker payudara berasal dari invasive carcinoma of no special type. Sel kanker berawal dari 
duktus dan menembus dinding duktus yang akhirnya menyebar ke organ lain seperti tulang. Penelitian yang dilakukan di Inggris menemukan bahwa dari 267 kasus kanker payudara dengan metastasis tulang, sebanyak 111 kasus merupakan tipe invasive carcinoma of no special type $(41,6 \%)$ dan 25 kasus $(9,3 \%)$ merupakan tipe invasive lobular carcinoma. ${ }^{11}$

Profil imunohistokimia dibagi menjadi empat yaitu estrogen reseptor (ER), progresteron reseptor (PR), HER-2, dan Ki67. Profil Ki67 dianggap rendah jika $<14 \%$ dan dianggap tinggi jika $\geq 14 \% .^{12}$ Subtipe molekuler kanker payudara dibagi mejadi empat bagian yaitu luminal $\mathrm{A}$, luminal $\mathrm{B}$, amplifikasi HER-2 dan triple negative berdasarkan profil imunohistokimia. Pemeriksaan subtipe berdasarkan profil imunohistokimia bertujuan untuk menentukan terapi endokrin dan prognosis pasien.

Subtipe yang paling banyak didapatkan pada penelitian ini ialah subtipe luminal $\mathrm{B}$ $(45,7 \%)$, disusul oleh luminal A $(32,6 \%)$, HER-2 positif (19,6\%), dan triple negative $(2,2 \%)$. Hasil penelitian ini menunjukkan kesesuaian dengan penelitian yang dilakukan di RSUP Dr. M. Djamil Padang, yang menyatakan bahwa luminal B merupakan subtipe yang paling banyak ditemukan yaitu sebanyak 38 kasus $(39,6 \%)$ disusul dengan amplifikasi HER-2 sebanyak 25 kasus. Hasil penelitian ini tidak sesuai pada parameter luminal A dan triple negative dengan penelitian sebelumnya yang mendapatkan triple negative lebih banyak $(22,9 \%)$ dibandingkan luminal A $(11,5 \%) .{ }^{13}$ Penelitian ini juga tidak sejalan dengan penelitian Xiong et $\mathrm{al}^{9}$ yang mendapatkan subtipe terbanyak ialah luminal A $(57,6 \%)$ disusul oleh luminal B $(12,9 \%)$, triple negative (8\%), dan yang terendah pada subtipe amplifikasi HER-2 $(5,1 \%)$. Ketidaksesuaian hasil penelitian ini terjadi karena pada penelitian sebelumnya reseptor Ki67 tidak dikategorikan saat penggolongan subtipe, dan penggolongan hanya berdasarkan ER/PR (+) dan HER-2 () tergolong luminal A; ER/PR (+) dan HER $(+)$ tergolong luminal $\mathrm{B}$; ER/PR (-) dan HER-2 (+) tergolong amplifikasi HER-2; dan ER/PR (-) dan HER-2 (-) tergolong triple negative. Penelitian oleh Xiao et al ${ }^{14}$ juga menunjukkan ketidaksesuaian dengan penelitian ini yaitu pada pasien kanker payudara dengan metastasis didapatkan subtipe terbanyak ialah subtipe Luminal A. Penelitian tersebut juga menggunakan penggolongan subtipe yang sama yaitu reseptor Ki67 tidak dimasukkan dalam kategori. Dengan demikian penggolongan subtipe yang berbeda akan menghasilkan temuan yang berbeda pula.

\section{SIMPULAN}

Kasus kanker payudara dengan metastasis tulang di RSUP Sanglah Denpasar Bali tahun 2014-2018 paling banyak terjadi pada kelompok usia 40-49 tahun, tipe invasive carcinoma of no special type dengan subtipe luminal B, dan lateralisasi kanan dan kiri yang tidak jauh berbeda.

\section{Konflik Kepentingan}

Penulis menyatakan tidak terdapat konflik kepentingan dalam studi ini.

\section{DAFTAR PUSTAKA}

1. Cardoso F, Harbeck N, Fallowfield L, Kyriakides S, Senkus E. Localy recurrent or metastatic breast cancer: esmo clinical practice guidelines for diagnosis, treatment and follow-up. Oxford University Press. 2011;22(6):25-30.

2. Mundy GR. Metastasis to bone: causes, consequences, and therapeutic opportunities. Nature Publishing Group. 2002;2:58493.

3. Komen SG. What is breast cancer? 2016. [online]. [cited 2017 July 2]. Available from: https://ww5.komen. org/uploaded Files/_Komen/Content/About_Breast_ Cancer/Tools_and_Resources/Fact_She ets_and_Breast_Self_Awareness_Cards /What\%20is\%20Breast\%20Cancer.pdf.

4. Mayo Clinic. Symptoms bone metastases. 2015. [online]. [cited 2017 June 29]. Available from: http://www.mayoclinic.org/ diseases-conditions/bone-metastasis/ basics/ symptoms/con-20035450.

5. Oncolink. All about bone metastases. 2016. [online]. [cited 2017 June 29]. Available from: https://www.oncolink.org/ cancers/bone/bone-metastases/all- 
about-bone-metastases.

6. Sucitra. Karakteristik penderita kanker payudara yang mengalami metastase ke tulang berdasarkan gejala klinis dan radiologi periode 2015-2017 di RSUP dr. Wahidin Sudirohusodo Makassar. 2017. [online]. [cited 2019 June 29]. Available from: http://digilib.unhas. ac.id/uploaded_files/temporary/Digital Collection/NDEwOWMOZTVmZmIz MDMxY2U4NjFkNWVjOGQxNmFl YzI0MzEwZWM2OA==.pdf.

7. Price SA, Wilson LM. Patofisiologi Konsep Klinis Proses-Proses Penyakit. Jakarta: EGC, 2006; p. 867-75.

8. Sinaga LE, Muda S, Rasmaliah. Karakteristik penderita kanker payudara yang dirawat inap di RS St. Elisabeth Medan tahun 2011-2013. Jurnal Gizi, Kesehatan Reproduksi dan Epidemiologi. 2014; 1(4):3-7.

9. Xiong Z, Deng G, Huang X, Li X, Xie X, Wang $\mathrm{J}$, et al. Bone metastasis pattern in initial metastatic breast cancer: a populationbased study. Cancer Manag Res. 2018; 10:289-93.

10. Rondonuwu IA, Haroen H, Wantania FE. Profil kanker payudara di RSUP Prof.
Dr. R. D. Kandou Manado tahun 20132014. e-CliniC. 2016; 4(1):304-9.

11. James J, Evans A, Pinder S, Gutteride E, Cheung K, Chan S, et al. Bone metastases from breast carcinoma: histopatological radiological correlations and prognostic features. British ournal of Cancer. 2003;89(4): 660-5.

12. Park S, Koo JS, Kim MS, Park HS, Lee JS, Lee JS, et al. Characateristic and outcome according to molecular subtypes of breast cancer as classified by a panel of four biomarkers using immunehistochemistry. The Breast. 2012;21(1): 50-7.

13. Irwan I, Azamris A, Bachtiar H. Perbandingan prognisis subtipe molekuler kanker payudara antara pasien kanker payudara usia muda dan tua Di RSUP DR. M. Djamil Padang. Jurnal Majalah Kedokteran Andalas. 2015;38(3):208-17.

14. Xiao W, Zheng S, Yang A, Zou Y, Tang H, Xie X. Breast cancer metastasis subtypes and risk of distant metastasis at initial diangnosis: a population-based study. Cancer Manag Res. 2018;10: 5332-4. 